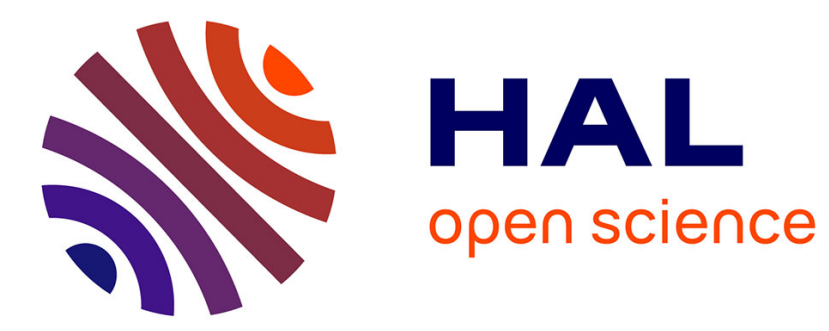

\title{
The Impact of Envy on Relational Employment Contracts
}

\author{
Jenny Kragl, Julia Schmid
}

\section{To cite this version:}

Jenny Kragl, Julia Schmid. The Impact of Envy on Relational Employment Contracts. Journal of Economic Behavior and Organization, 2009, 72 (2), pp.766. 10.1016/j.jebo.2009.07.016 . hal00723632

\section{HAL Id: hal-00723632 \\ https://hal.science/hal-00723632}

Submitted on 12 Aug 2012

HAL is a multi-disciplinary open access archive for the deposit and dissemination of scientific research documents, whether they are published or not. The documents may come from teaching and research institutions in France or abroad, or from public or private research centers.
L'archive ouverte pluridisciplinaire HAL, est destinée au dépôt et à la diffusion de documents scientifiques de niveau recherche, publiés ou non, émanant des établissements d'enseignement et de recherche français ou étrangers, des laboratoires publics ou privés. 


\section{Accepted Manuscript}

Title: The Impact of Envy on Relational Employment Contracts

Authors: Jenny Kragl, Julia Schmid

PII: $\quad$ S0167-2681(09)00185-1

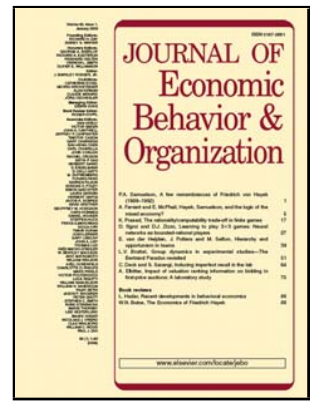

DOI: $\quad$ doi:10.1016/j.jebo.2009.07.016

Reference: $\quad$ JEBO 2422

To appear in: Journal of Economic Behavior \& Organization

Received date: $\quad 25-10-2007$

Revised date: 20-7-2009

Accepted date: $\quad$ 20-7-2009

Please cite this article as: Kragl, J., Schmid, J., The Impact of Envy on Relational Employment Contracts, Journal of Economic Behavior and Organization (2008), doi:10.1016/j.jebo.2009.07.016

This is a PDF file of an unedited manuscript that has been accepted for publication. As a service to our customers we are providing this early version of the manuscript. The manuscript will undergo copyediting, typesetting, and review of the resulting proof before it is published in its final form. Please note that during the production process errors may be discovered which could affect the content, and all legal disclaimers that apply to the journal pertain. 


\title{
The Impact of Envy on Relational Employment Contracts ${ }^{\text {th }}$
}

\author{
Jenny Kragl ${ }^{*, a}$, Julia Schmid ${ }^{\mathrm{b}}$ \\ ${ }^{a}$ European Business School (EBS) Wiesbaden, Department of Law, Governance 8 \\ Economics, Soehnleinstr. 8A, D-65201 Wiesbaden, Germany \\ ${ }^{b}$ Technical University Berlin, Department of Economics and Management, Straße des 17. \\ Juni 135, D-10623 Berlin, Germany
}

\begin{abstract}
We study the effects of envy on relational employment contracts in a standard moral hazard setup with two agents. Performance is evaluated via an observable, but non-contractible signal which reflects an agent's individual contribution to firm value. Both agents exhibit horizontal disadvantageous inequity aversion. In contrast to the literature, we find that inequity aversion may be beneficial; in the presence of envy, for a certain range of interest rates, relational contracts may be more profitable. For some interest rates reputational equilibria exist only with envious agents.
\end{abstract}

Key words: principal-agent, relational contract, inequity aversion, envy JEL: D63, D82, M52, M54

\footnotetext{
This paper is a revised chapter of a doctoral thesis on fairness concerns in relational contracts at the Humboldt-Universität zu Berlin. We would like to thank Dominique Demougin, Florian Englmaier, Oliver Fabel, Carsten Helm, Martin Kliem, Dorothea Kübler, Gerd Muehlheusser, Klaus Schmidt, and Anja Schöttner for helpful comments and discussions. An earlier version of this paper was circulated under the title "Relational Contracts and Inequity Aversion" (SFB 649 Discussion Paper 2006-085). It was presented at the Annual Meetings of the EEA 2007, the EALE 2007, and the Verein für Socialpolitik 2007. Financial support by the Deutsche Forschungsgemeinschaft through the Collaborative Research Center 649 "Economic Risk" is gratefully acknowledged.

${ }^{*}$ Corresponding author. Tel. +49 61136018655 , Fax +49 61136018602

Email addresses: jenny.kragl@ebs.edu (Jenny Kragl), j.schmid@ww.tu-berlin.de (Julia Schmid)
} 
"Implicit contracts can be effective only in a social atmosphere that incorporates a sense of mutual respect and a consensus on principles of fair play and good faith."

Arthur M. OKun ${ }^{1}$

\section{Introduction}

The present paper investigates how concerns for fairness among agents affect the optimal provision of incentives in a one-task framework with only subjective performance measures. In particular, we analyze the impact of horizontal disadvantageous inequity aversion on the principal's credibility in a relational contract. So far the literature has focused on the impact of inequity aversion on the design of explicit incentive contracts. In these environments, employing inequity averse agents comes at a cost for the principal. In contrast to that, we find that with implicit incentives, the principal might prefer to employ inequity averse, rather than inequity neutral, agents.

Frequently, if not typically, the agent's true contribution to firm value cannot be objectively assessed. In many cases, his contribution can, nonetheless, be observed by both contracting parties. The observed subjective performance may be used in implicit agreements (relational contracts). As subjective assessments are not verifiable by third parties, contracts are not courtenforceable and thus have to be self-enforcing. They may be implemented in long-term relationships as reputational equilibria. ${ }^{2}$

So far the literature on relational contracts has primarily focused on problems under symmetric information. ${ }^{3}$ Apart from that, there is an evolving literature analyzing self-enforcing contracts under asymmetric information, in particular moral hazard in effort (Baker et al., 1994, 2002; Levin, 2003; Kvaløy and Olsen, 2006; Schöttner, 2008). We contribute to the latter strand of literature by analyzing fairness concerns that may arise in multilateral contracting under ex-post asymmetric information.

\footnotetext{
${ }^{1}$ Okun (1980), p. 8.

${ }^{2}$ Reputational equilibria may exist if one party cares about her reputation in future relationships. See e.g. Holmström (1981) or Baker et al. (2002).

${ }^{3}$ See e.g. Bull (1987), MacLeod and Malcomson (1989), and Levin (2002).
} 
As the agents' contributions to firm value are not necessarily perfectly correlated to their efforts, agents undertaking the same effort could receive different rewards. This might provoke envy, empathy, or spiteful behavior among agents, especially if they work on similar tasks. ${ }^{4}$ Taking into account the presence of envy among agents, we investigate the feasibility and profitability of relational contracts.

We consider an employment relationship between one principal and two risk neutral, not financially constrained agents who exhibit disadvantageous inequity aversion. We have in mind employees working on similar tasks in small or medium-size firms or divisions where workers tend to compare their payoffs with those of their colleagues. ${ }^{5}$ Specifically, we model preferences as "self-centered inequity aversion", as proposed by Fehr and Schmidt (1999), abstracting from empathy. ${ }^{6}$ Neither agent's effort is directly observable by the principal, albeit imperfectly correlated with individual performance. The principal seeks to mitigate the resulting moral hazard problem by offering each agent an incentive contract contingent on their respective performances. As observed performance is not verifiable, the contract has to be self-enforcing; i.e., reputation concerns have to restrain the principal from deviating from the incentive contract.

It is well known that, with explicit incentives, more envious agents exert more effort than less envious ones when being offered identical incentive contracts (Grund and Sliwka, 2005; Demougin and Fluet, 2006). However, to ensure participation, the principal has to pay the inequity averse agents a premium to compensate them for the faced risk of unequal payoffs (inequity premium). In this kind of framework, agency costs increase in the presence of inequity aversion as reported by, e.g., Bartling and von Siemens (2007) and Grund and Sliwka (2005). ${ }^{7}$ Both results are true for our model as long

\footnotetext{
${ }^{4}$ For experimental evidence of other-regarding preferences see e.g. Goranson and Berkowitz (1966), Berg et al. (1995), Fehr et al. (1998), and Fehr et al. (1997).

${ }^{5}$ E.g., according to a survey study by Bewley (1998), workers indeed compare themselves with other workers within their firm whereas workers' pay in other firms has little effect. While an agent may also care about the principal's well-being (vertical inequity aversion), we are interested in inequity averse preferences among agents within the firm and the effects thereof for the optimality of employment schemes.

${ }^{6}$ For alternative approaches regarding the formalization of fairness concerns see e.g. Rabin (1993), Bolton and Ockenfels (2000), and Falk and Fischbacher (2006).

${ }^{7}$ This holds under unlimited liability which is the case we consider. Under limited
} 
as only one period is considered. Here, the principal would rather employ inequity neutral than inequity averse agents.

The present paper analyzes how this conclusion is affected under a relational contract. The principal's credibility constraint requires that her gains from reneging fall short of the discounted gains from continuing the relational contract. We find that this constraint is ambiguously affected by the presence of envy; on the one hand, the incentive for the principal to deviate from the relational contract in order to save bonus expenses decreases in the propensity for envy. Intuitively, this is due to the fact that envious agents work harder given the same incentive in order to avoid ending up with a lower payoff than their colleagues. This facilitates credible commitment on the principal's side. On the other hand, as agents have to be compensated for their disutility incurred by envy, the principal's long-run profits out of the contract decrease as agents become more envious. Consequently, commitment to paying the offered bonus is more difficult.

The sum of these two counteracting effects determines whether credibility is either more or less easily obtained by the principal as agents become more envious. Whenever the savings due to lower bonus payments exceed the loss of future profits via the inequity premium, credibility is enhanced by the degree of envy and, for some range of discount rates, the principal prefers to employ more envious agents.

We identify a necessary and sufficient condition under which, for a range of the principal's discount rate, relational contracts are less profitable, or even infeasible, when agents do not exhibit any disadvantageous inequity aversion. In that case, envy becomes an advantageous factor in principal-agent relationships in the sense that it softens the principal's credibility constraint and more reputational equilibria can be sustained with envious agents.

Our findings underline that empirically observed cultural differences in social preferences should not be neglected in organizational decisions when firms rely on implicit incentives. In particular, the implementation of relational employment contracts might not be possible with inequity neutral

liability, it might not be true; wage costs may decrease in the agents' inequity aversion as long as they receive rents. See e.g. Demougin and Fluet $(2003,2006)$. 
agents if the principal's discount rate is relatively low. Moreover, relational contracts might be more profitable in countries where people generally exhibit a greater degree of inequity aversion due to cultural differences. For example, Alesina et al. (2004) and Corneo (2001) find Europeans to exhibit a higher propensity for inequity aversion in comparison to U.S. Americans. ${ }^{8}$

Thus, the implementation of relational contracts might be more frequent in countries whose populations are more sensitive to inequity aversion. Taking cultural differences in the degree of inequity aversion into consideration, our findings support the empirical analysis by Moriguchi (2005). She argues that relational contracts are more prevalent in Japan than in the United States, pointing out that the United States were hit harder by the Great Depression compared to Japan. This goes along with lower continuation profits and thus results in the less frequent use of relational contracts in the United States. According to our analysis, a depreciation of future profits may have a less severe impact on the feasibility of relational contracts if employees are more strongly inequity averse. Hence, these countries' differences in the propensity for inequity aversion could also play a role for the explanation of differences in institutional arrangements in this context.

Before proceeding with the analysis, two caveats are in order. First, our main analysis focuses on individual bonus schemes. However, other contracts, such as peer-dependent compensation schemes, might possibly be implemented. We discuss the benefits and drawbacks of rank-order tournaments and team bonus contracts within our setting in a supplemental section and relate the findings to the results for the individual bonus scheme.

Second, one has to be aware of the fact that for an individual's perception of fairness and equity, many determinants beside the colleague's payoff may play a role: e.g. effort, ability, education, gender, status etc. Cognition of inequity is presumably affected by mutual comparisons regarding all the mentioned characteristics. In our model, due to the agents' homogeneity in both preferences and characteristics, differences in payoffs are the sole source of inequity. Hence, payoff inequality accords with inequity.

\footnotetext{
${ }^{8}$ For a recent empirical cross-country investigation of preferences for redistribution see Isaksson and Lindskog (2007). The study's findings suggest that Swedish, Hungarian, and German people are more supportive of redistribution than U.S. Americans.
} 
The next section describes our basic framework. Subsection 2.1 addresses the agency problem in the single-period game. Subsection 2.2 develops the reputation game, and thereby the relational contract. In section 3, we examine the impact of the agents' propensity for envy on the relational contracts and derive our main results concerning the principal's credibility problem. Section 4 discusses alternative compensation schemes. Section 5 concludes.

\section{The Model}

We consider a repeated game between a principal (the firm) and two agents who are homogeneous in preferences and characteristics. ${ }^{9}$ In each period, agent $i, i=1,2$, chooses an unobservable effort level $e_{i}$ that stochastically determines the agent's contribution to firm value $Y_{i}$. That contribution is either high or low; $Y_{i} \in\{0,1\}$. The signal $Y_{i}$ is observable by all three contracting parties but not verifiable; it can therefore only be used as a performance measure in a self-enforcing relational contract. By exerting effort agent $i$ affects the probability of $Y_{i}=1$ :

$$
\operatorname{Pr}\left[Y_{i}=1 \mid e_{i}\right]=p\left(e_{i}\right)
$$

where $p\left(e_{i}\right) \in[0,1), p(0)=0, p^{\prime}\left(e_{i}\right)>0$, and $p^{\prime \prime}\left(e_{i}\right)<0$. The agents' outputs are stochastically independent.

The principal offers each agent an individual incentive contract consisting of a fixed wage $w$ and a per-period bonus $b$ to be paid if a favorable signal is detected in that respective period. ${ }^{10}$ Provided that the principal keeps her promise, the bonus is paid whenever she observes $Y_{i}=1$. Thus, an agent's net monetary payoff is

$$
\pi_{i}-c\left(e_{i}\right)=w+b Y_{i}-c\left(e_{i}\right)
$$

where $c\left(e_{i}\right)$ denotes each agent's costs of effort with $c(0)=0, c^{\prime}(0)=0$, $c^{\prime}\left(e_{i}\right)>0 \forall e_{i}>0$, and $c^{\prime \prime}\left(e_{i}\right) \geq 0$.

\footnotetext{
${ }^{9}$ Equivalently, we could assume the principal to employ many agents and approach the problem from the perspective of one agent, all other agents forming his reference group.

${ }^{10}$ That is, we consider payment schemes without memory.
} 
Following Fehr and Schmidt (1999), both agents exhibit inequity aversion. In particular, we assume them to suffer only from disadvantageous inequity, i.e., they dislike outcomes where they are worse off than the respective other agent. Each agent observes the other agent's gross monetary payoff. All parties are risk neutral and not financially constrained. For simplicity, the agents' utilities are assumed to be linear in money. Altogether, agent $i$ 's per-period utility is given by

$$
U_{i}\left(\pi_{i}, \pi_{j}\right)=\pi_{i}-c\left(e_{i}\right)-\alpha \max \left\{\pi_{j}-\pi_{i}, 0\right\}, \quad i \neq j
$$

where $\alpha \geq 0$ denotes the agents' propensity for envy. The third term thus captures the disutility derived from being worse off than agent $j .^{11}$

The timing of events within a period is as follows. At the beginning of the period, the principal offers each agent the above specified compensation contract. Second, the agents either accept the contract or reject it in favor of an alternative employment opportunity that provides utility $U_{0}$. Third, if the agents accept the contract, they simultaneously choose respective effort levels $e_{i}$. Fourth, $Y_{i}$ is realized and observed by all parties. Finally, the agents receive the explicit fixed wage, and if $Y_{i}=1$ the principal decides whether or not to pay the implicit bonus.

\subsection{The Single-Period Game}

To derive the relational contract, we initially consider the single-period game where we assume performance to be objectively assessable, i.e., there is no credibility problem on the principal's side. Given that agent $j$ exerts effort $e_{j}$, agent $i$ 's expected utility is

$$
E\left[U_{i} \mid e_{i}, e_{j}\right]=w+p\left(e_{i}\right) b-c\left(e_{i}\right)-\alpha\left(1-p\left(e_{i}\right)\right) p\left(e_{j}\right) b, \quad i \neq j,
$$

\footnotetext{
${ }^{11}$ Abstracting from costs, Fehr and Schmidt (1999) propose the following utility function: $U_{i}=\pi_{i}-\alpha \max \left\{\pi_{j}-\pi_{i}, 0\right\}-\beta \max \left\{\pi_{i}-\pi_{j}, 0\right\}, \alpha>\beta \geq 0$. Incorporating empathy via the parameter $\beta$ would not affect our results qualitatively. For a brief discussion of status preferences, $\beta<0$, see section 5. Moreover, Demougin and Fluet (2006) take costs into account when investigating inequity: $U_{i}=\pi_{i}-c\left(e_{i}\right)-\alpha \max \left\{\pi_{j}-c\left(e_{j}\right)-\pi_{i}+c\left(e_{i}\right), 0\right\}$. This would change our results neither. However, an inconvenient discontinuity at the symmetric Nash equilibrium would be introduced.
} 
where the last term captures the expected disutility from disadvantageous inequity amounting to the difference in payoffs $b$. A symmetric Nash equilibrium is characterized by

$$
e=\arg \max _{\widehat{e}} E\left[U_{i} \mid \widehat{e}, e\right] .
$$

In the Appendix, we verify that there exists a symmetric Nash equilibrium which is also unique. In equilibrium, the first-order condition yields

$$
p^{\prime}(e) b-c^{\prime}(e)+\alpha p^{\prime}(e) p(e) b=0 .
$$

Thus, given that the agents exhibit disadvantageous inequity aversion and are faced with a contract with bonus $b$, they will undertake effort $e$, given that (IC) is satisfied at $e$. Implicitly this defines a function

$$
b(e ; \alpha)=\frac{c^{\prime}(e)}{(1+\alpha p(e)) p^{\prime}(e)} .
$$

Proposition 1. Under an individual bonus scheme, with an increasing propensity for envy, the agents exert more effort for any given bonus.

Proof. Applying the implicit-function theorem to (IC) yields

$$
\frac{d e}{d \alpha}=-\frac{p^{\prime}(e) p(e) b}{p^{\prime \prime}(e) b(1+\alpha p(e))-c^{\prime \prime}(e)}>0 .
$$

Intuitively, as envious agents suffer from being worse off than their coworkers as opposed to non-envious agents, they exert relatively higher levels of effort in order to decrease the probability of not getting the bonus. This incentive-strengthening effect is in line with Demougin and Fluet (2006). ${ }^{12}$ In the remainder of the paper, we will refer to it as the incentive effect.

\footnotetext{
${ }^{12}$ In the context of tournaments, Grund and Sliwka (2005) and Demougin and Fluet (2003) report the same result. Kräkel (2008) identifies an incentive-strenghthening effect when emotions play a role in tournaments.
} 
The principal's profit per agent $i$ is $V_{b}=(1-b) Y_{i}-w$. Hence, in the one-shot game, she sets $b, w$, and $e$ to maximize expected profit per agent subject to participation and incentive compatibility constraints:

$$
\begin{array}{ll}
\max _{b, w, e} & (1-b) p(e)-w \\
\text { s.t. } & E\left[U_{i} \mid e\right] \geq U_{0}, \\
& b p^{\prime}(e)-c^{\prime}(e)+\alpha p^{\prime}(e) p(e) b=0
\end{array}
$$

Since we assume unlimited liability, the participation constraint binds, leading to zero rent for the agents in the optimal contract. In equilibrium, for each agent we have

$$
w+p(e) b=c(e)+\alpha(1-p(e)) p(e) b+U_{0} .
$$

The second term on the right-hand side in equation (9) is the inequity premium. Hence, expected wage costs per agent are equal to the sum of his costs of effort, his reservation utility, and the inequity premium. Substituting $w$ and $b$ in the principal's objective function by using (9) and (6), her problem simplifies to

$$
\max _{e} V_{b}(e ; \alpha)=p(e)-c(e)-\alpha p(e)(1-p(e)) \frac{c^{\prime}(e)}{(1+\alpha p(e)) p^{\prime}(e)}-U_{0} .
$$

Let $e^{*}$ denote the effort level that maximizes the principal's expected oneperiod profit $V_{b}(e ; \alpha)$.

Proposition 2. Suppose that performance is verifiable. Then under an individual bonus scheme,

(i) the first-best solution is obtained if agents are not envious, $\alpha=0$.

(ii) the first-best solution can never be obtained if agents exhibit a propensity for envy, $\alpha>0$.

(iii) total agency costs increase as agents become more envious.

Proof. As for the first part of the claim (i), observe that with $\alpha=0$, the principal's objective function (10) is

$$
V_{b}(e ; 0)=p(e)-c(e)-U_{0}
$$


Optimization with respect to effort requires marginal productivity to equal marginal costs of effort such that the first-best effort level $e=e^{F B}$ is implemented. To prove (ii), with $\alpha>0$, in problem (10) the derivative of the inequity premium, $\alpha p(e)(1-p(e)) c^{\prime}(e) \cdot\left((1+\alpha p(e)) p^{\prime}(e)\right)^{-1}$, with respect to effort is non-zero. Hence, profit-maximizing effort cannot be first-best. As to (iii), using the envelope theorem, observe that the derivative of (10) w.r.t. $\alpha$ is negative as $-\frac{c^{\prime}(e)}{p^{\prime}(e)} \frac{p(e)(1-p(e))}{(p(e) \alpha+1)^{2}}<0$.

For the case of non-envious agents, the individual bonus scheme involves zero agency costs. However, when agents are envious the principal faces positive agency costs despite the incentive effect. This result is due to the fact that the principal needs to compensate the agents for the expected disutility from inequity in order to ensure participation. We refer to this wage costaugmenting effect as the inequity premium effect. This result is in line with the literature, see e.g. Bartling and von Siemens (2007) and Grund and Sliwka (2005).

\subsection{The Repeated Game}

To model the relational contract, we embed the foregoing stage game into an infinitely repeated game, considering trigger strategy equilibria. If the principal reneges on the promised bonus once, no agent will ever again believe her to fulfill the contract. ${ }^{13}$ Hence, the principal's reputation is decisive for her ability to implement relational contracts.

As effort is not observable, agents will exert zero effort if relational contracts are infeasible, corresponding to a closure of the firm and resulting in a fallback profit of zero. If relational contracts are feasible, the principal realizes a continuation profit from the long-term relationship, corresponding to expected profit $V_{b}(e ; \alpha)$ defined in $(10)$.

For the relational contract to be self-enforcing, the gains from reneging must fall short of the gains from continuing the relational contract. This is

\footnotetext{
${ }^{13}$ Implicitly, we assume that the information on a principal's deviation from the relational contract is rapidly transmitted to the labor market. As Baker et al. (1994) note, each agent in the employment relationship could alternatively be represented by an infinite sequence of agents, each of whom lives for one period, provided that each period's agent learns the history of play before the period begins. See also Bull (1987) for the role of reputation in implicit contracts.
} 
required to hold for all realizations of performance. If both agents perform successfully, $Y_{i}=Y_{j}=1$, the principal's incentive to renege on the relational contract is strongest as her resulting one-time benefit from deviation amounts to twice the bonus. Concerning her reputation, it does not make any difference whether she refuses to pay just one or both bonuses. Thus, due to the separability of the profit function across workers

$$
b(e ; \alpha) \leq \frac{V_{b}(e ; \alpha)}{r}
$$

constitutes the credibility constraint of the principal (CC). ${ }^{14}$ The optimal relational contract implements $e$ to maximize the principal's expected profit per period, subject to her credibility constraint:

$$
V_{b}^{*}(r, \alpha):=\max _{e} V_{b}(e ; \alpha) \text {, s.t. (CC) }
$$

Whether condition (CC) can be satisfied or not, depends on the firm's interest rate $r$. To shed light on the interest rate's impact on the optimal relational contract we illustrate the credibility constraint with the help of an example in Figure 1. Specifically, we assume $\alpha=0.2, p(e)=1-\exp (-e), c(e)=\frac{1}{8} e^{2}$, and $U_{0}=0.1$. The figure plots the principal's expected per-period profit $V_{b}(e ; \alpha)$. Moreover, the convex curves depict $r b(e ; \alpha)$ for various discount rates.

For a sufficiently low interest rate the credibility constraint does not bind. Equivalently to the case of verifiable performance, the optimal relational contract implements the profit-maximizing benchmark effort level $e^{*}$. We denote the threshold interest rate for which (CC) becomes binding $\underline{r}$. The dashed line illustrates $\underline{r} b(e ; \alpha)$.

The solid curve depicts $r b(e ; \alpha)$ for a medium interest rate where $(\mathrm{CC})$ is binding. To ensure credibility on the one hand and to maximize profits

\footnotetext{
${ }^{14}$ We derive the rationality constraint analogously to Baker et al. (1994). Note that the interest rate $r$ may be translated into the firm's discount rate $\delta$ referring to, e.g., its patience. Then $r=(1-\delta) / \delta$. Hart (2001) emphasizes the discount rate's interpretation as a measure for dependency or trust between the transacting parties. Alternatively, $r$ can be reinterpreted in terms of the likelihood that the firm disappeares from the market, $\rho$. In that case $r=\rho /(1-\rho)$.
} 


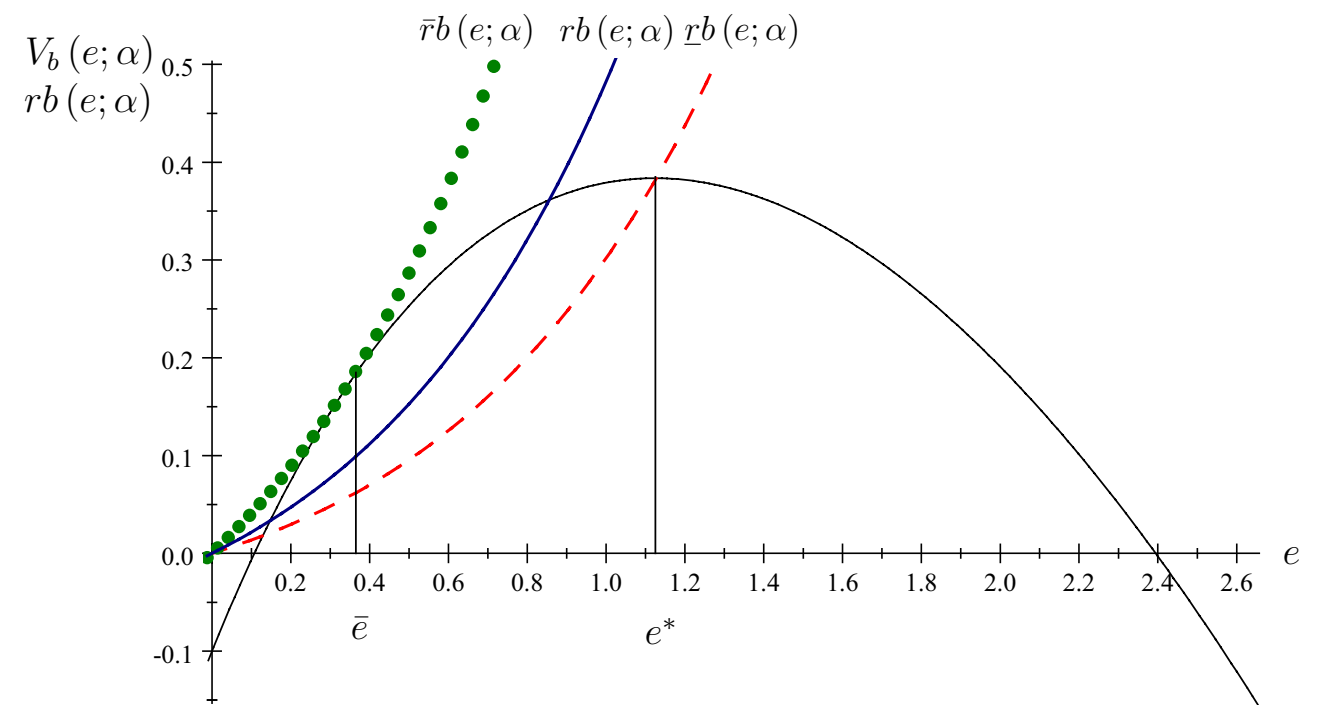

Figure 1: Credibility Constraint for $p(e)=1-\exp (-e), \alpha=0.2, c(e)=\frac{1}{8} e^{2}$, and $U_{0}=0.1$.

on the other hand, the principal will always choose to implement the maximum effort level that just satisfies condition (CC). Geometrically, it is given by the highest possible effort level for which $V_{b}(e ; \alpha)$ and $r b(e ; \alpha)$ intersect. The figure illustrates that the optimal effort level declines as the principal's interest rate or the agents' alternative utilities increase. Intuitively, raising the interest rate implies the present value of contract continuation to decrease. Therefore the principal has to reduce the bonus in order to remain credible which implies the implementation of a lower effort level. Analogous arguments apply to an increase in the alternative utility.

As long as the credibility constraint can be fulfilled via adjustment of the implemented effort level for some given $r$, contracts are feasible. For a sufficiently high interest rate condition (CC) can no longer be satisfied. The marginal interest rate $\bar{r}$ for which (CC) can just be fulfilled is characterized by $\bar{r} b(e ; \alpha)$ being tangent to $V_{b}(e ; \alpha)$. We denote the effort level implemented at this threshold $\bar{e}$. Relational contracts are infeasible for any interest rate larger than the threshold interest rate $\bar{r}$. The dotted line, $\bar{r} b(e ; \alpha)$, represents this marginal case. 


\section{The Impact of Envy on the Optimal Relational Bonus Contract}

In this section, we analyze the effect of the agents' propensity for envy on the profitability and feasibility of the optimal relational contract. Closer examination of condition (CC) reveals the impact of envy to be twofold. On the one hand, as shown in Proposition 1, we observe the incentive effect; $\frac{d e}{d \alpha}>0$. For a given effort level, it implies that the principal can reduce the bonus as agents become more envious. ${ }^{15}$ Consequently, the incentive of a one-time deviation from the relational contract in order to save bonus expenses decreases. On the other hand, the inequity premium effect lowers the principal's profit from contract continuation; $\frac{\partial V_{b}(e ; \alpha)}{\partial \alpha}<0$, as shown in Proposition 2. Thus, fulfilling the relational contract is less attractive to the principal.

Depending on the overall impact of the agents' propensity for envy on the credibility constraint, the marginal interest rate $\bar{r}$ increases or decreases. The larger this interest rate is, the greater is the range of interest rates for which the principal may credibly commit and relational contracts are feasible.

Both $\bar{r}$ and $\bar{e}$ are implicitly defined as the solution of the following $2 \times$ 2 - system consisting of the binding credibility constraint and the tangency condition (see Figure 1):

$$
\begin{gathered}
r=\frac{V_{b}(e ; \alpha)}{b(e ; \alpha)} \\
r \frac{\partial b(e ; \alpha)}{\partial e}=\frac{\partial V_{b}(e ; \alpha)}{\partial e}
\end{gathered}
$$

Conducting a comparative-statics analysis of $\bar{r}$ with respect to $\alpha$, we derive the following result.

Proposition 3. Suppose that performance is non-verifiable. Then an increasing propensity for envy may enhance the feasibility of the relational contract. This is the case, if and only if, at $e=\bar{e}$, the following condition holds:

$$
p(e)>\frac{\left(c(e)+U_{0}\right) p^{\prime}(e)+c^{\prime}(e)}{p^{\prime}(e)+c^{\prime}(e)} .
$$

\footnotetext{
${ }^{15}$ Mathematically, this follows from equation (6) as $\frac{\partial b(e ; \alpha)}{\partial \alpha}<0$.
} 
Proof. See the Appendix.

The necessary and sufficient condition (14) assures that the incentive effect outweighs the inequity premium effect regarding the credibility constraint. The principal's incentive to renege on the bonus payments is sufficiently small such that the negative impact of envy on the continuation profit is overcompensated. Intuitively, the condition requires the continuation profit $V_{b}$ to react less strongly to an increase in the degree of envy than the bonus payment $b .{ }^{16}$ Note that satisfaction of the condition demands the sum of effort costs and alternative utility to be smaller than unity which is inherently fulfilled due to the model setup. ${ }^{17}$ The smaller this sum the more probable the feasibility-enhancing effect of envy is to arise and the stronger the effect is. ${ }^{18}$ Further, from condition (14) can be inferred that the effect is more likely to exist if the precision of the signal is large and the effort elasticity of costs is small. ${ }^{19}$

Thus, we find that a high propensity for envy may be advantageous for the principal regarding her commitment power. Under the above condition (14), reputational equilibria can be sustained for a greater range of interest rates with envious agents, i.e., the credibility constraint is softened. Hence, there exist cases where the principal can build up a long-term contractual relationship with inequity averse agents and realize profits whereas with inequity neutral agents this is impossible.

Figure 2 qualitatively illustrates our results for the case that condition (14) is satisfied and, hence, the marginal interest rate $\bar{r}$ increases in the

\footnotetext{
${ }^{16}$ Mathematically, by equation (30), this is the case if the continuation-profit elasticity is smaller in absolute terms than the bonus elasticity both with respect to the degree of envy; $\left|\frac{\partial V_{b}}{\partial \alpha} \frac{\alpha}{V_{b}}\right|<\left|\frac{\partial b}{\partial \alpha} \frac{\alpha}{b}\right|$.

${ }^{17}$ To verify this observe that the principal's expected profit (10) becomes negative once $p(e)<c(e)+\alpha p(e)(1-p(e)) b(e ; \alpha)+U_{0}$. In this case, the principal would not engage in the contract. Moreover, $p(e)$ may not exceed unity. Accordingly, $c(e)+U_{0}$ can never be greater than unity.

${ }^{18}$ In the Appendix, we illustrate the impact of the alternative utility and the cost function on the effect's magnitude with the help of a numerical example. It reveals the effect to increase with decreasing $U_{0}$ and $c(e)$.

${ }^{19}$ Note that condition (14) can be reformulated in terms of elasticities with respect to effort: $p(e)>\left(\left(c(e)+U_{0}\right) \theta p(e)+\beta c(e)\right) /(\theta p(e)+\beta c(e))$, where $\theta$ denotes the elasticity of the success probability, i.e., the precision of the signal, and $\beta$ is the elasticity of costs.
} 
agents' propensity for envy. The figure shows the principal's profit under the optimal relational contract, $V_{b}^{*}(r ; \alpha)$, for any level of $r$ and two degrees of envy, $\alpha_{L}<\alpha_{H}$. The solid curve depicts her profit if agents exhibit a certain propensity for envy captured by $\alpha_{L}$. The dashed curve depicts her profit for agents with a higher propensity for envy, $\alpha_{H} \cdot{ }^{20}$

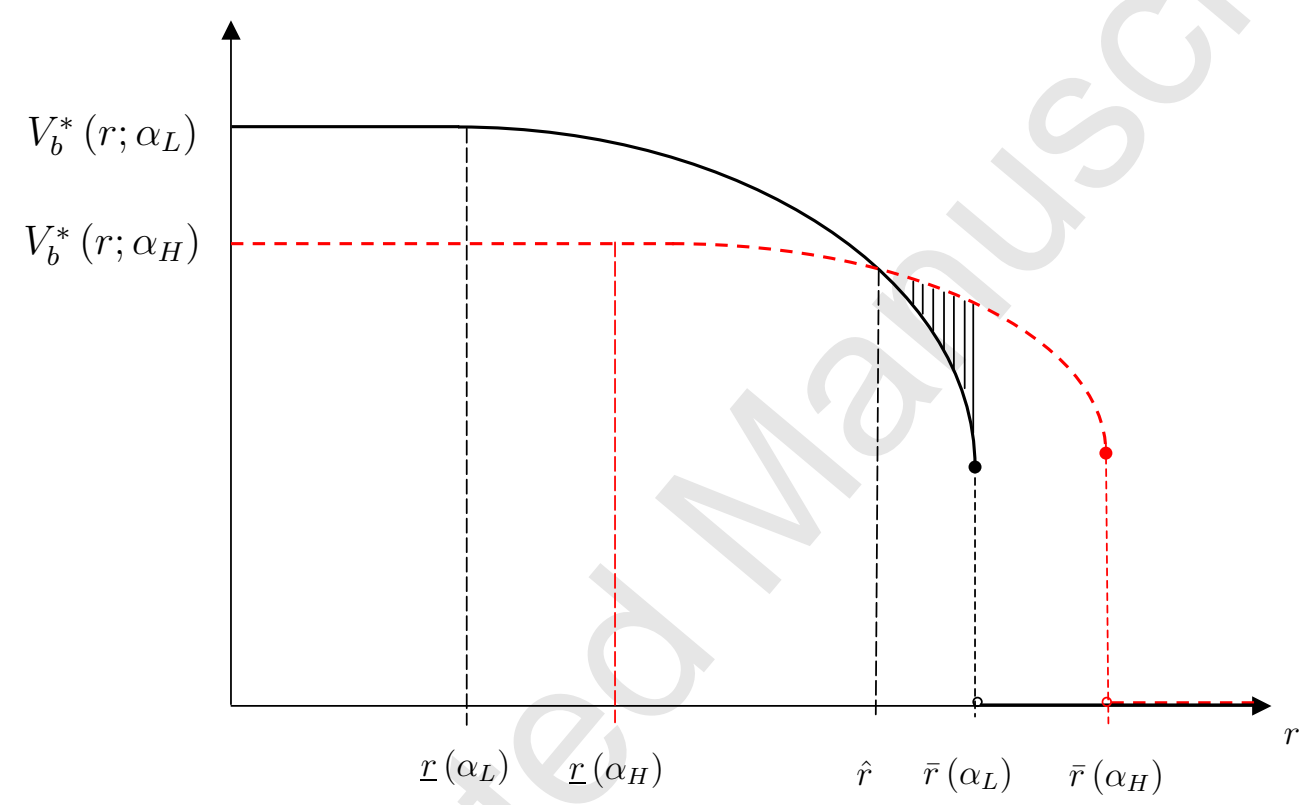

Figure 2: Profits for two degrees of envy, $\alpha_{H}>\alpha_{L} \geq 0$, when condition (14) is satisfied.

As can be seen in the figure, for a given propensity for envy $\alpha$ and sufficiently low interest rates $r$, i.e., interest rates below the lower interest threshold, $r \leq \underline{r}(\alpha)$, a relational contract is feasible and the optimal effort level $e^{*}$ is implemented by the principal; $V_{b}\left(e^{*} ; \alpha\right)$ is realized. For a range of interest rates, $\underline{r}(\alpha)<r \leq \bar{r}(\alpha)$, effort $e$ is adapted such that credibility requirements are fulfilled. Profits in the optimum, $V_{b}(e ; \alpha)$, decrease in this range as the interest rate increases. Once the interest rate is larger than the upper interest threshold, $r>\bar{r}(\alpha)$, the credibility constraint can no longer be satisfied

\footnotetext{
${ }^{20}$ The figure illustrates the case where the two degrees of envy are not too different. The case of a large difference in envy is discussed in the text below.
} 
by a reduction pf the induced effort level. ${ }^{21}$ Hence, relational contracts are infeasible, and profits drop to zero.

Considering two degrees of envy, $\alpha_{H}>\alpha_{L} \geq 0$, the foregoing results allow for conclusions regarding the relative profitability of the relational contracts. As illustrated by Figure 2, the relative performance of the contracts depends on the degrees of envy and the firm's interest rate. In particular, Proposition 2 implies that for any $r<\underline{r}\left(\alpha_{L}\right)$ profits with less envious agents exceed those with more envious agents; $V_{b}^{*}\left(r, \alpha_{H}\right)<V_{b}^{*}\left(r, \alpha_{L}\right)$.

Moreover, by Proposition 3, the upper interest threshold $\bar{r}(\alpha)$ is increasing in $\alpha$, implying that $\bar{r}\left(\alpha_{L}\right)<\bar{r}\left(\alpha_{H}\right)$. For any $r$ in-between the two upper thresholds, i.e., $r \in\left(\bar{r}\left(\alpha_{L}\right), \bar{r}\left(\alpha_{H}\right)\right]$, relational contracts are feasible with more envious agents whereas the principal cannot credibly commit herself when dealing with less envious ones. Thus positive profits are realized only with the former; $V_{b}^{*}\left(r, \alpha_{H}\right)>V_{b}^{*}\left(r, \alpha_{L}\right)=0$.

Combining Propositions 2 and 3 thus implies that there exists a critical value $\widehat{r}$ with $\underline{r}\left(\alpha_{L}\right)<\widehat{r} \leq \bar{r}\left(\alpha_{L}\right)$ such that for any $r \in\left(\widehat{r}, \bar{r}\left(\alpha_{H}\right)\right]$ continuation profits from employing more envious agents exceed those from employing less envious ones; $V_{b}^{*}\left(r, \alpha_{H}\right)>V_{b}^{*}\left(r, \alpha_{L}\right)$.

Concerning the value of $\widehat{r}$, one can distinguish two cases that depend on the particular difference in the degrees of envy. The case of a sufficiently small difference is illustrated in Figure 2. Observe that in the figure $V_{b}^{*}\left(\bar{r}\left(\alpha_{L}\right), \alpha_{H}\right)>V_{b}^{*}\left(\bar{r}\left(\alpha_{L}\right), \alpha_{L}\right)$. Thus, the two profit curves intersect at a value $\widehat{r}<\bar{r}\left(\alpha_{L}\right)$, and there is a region of interest rates for which continuation profits from employing more envious agents exceed those from employing less envious ones even if contracts with both types of agents are feasible (shaded area). ${ }^{22}$

If, however, the difference in the degrees of envy is sufficiently large, the figure looks slightly different. Then the dashed curve lies below the solid one

\footnotetext{
${ }^{21}$ See the Appendix for numerical examples of the lower and upper interest thresholds; $\underline{r}(\alpha)$ and $\bar{r}(\alpha)$.

${ }^{22}$ For the example functions used in Figure 1 and, e.g., values of $\alpha_{L}=0.2, \alpha_{H}=0.8$ or $\alpha_{L}=2.5, \alpha_{H}=3.0 \mathrm{such}$ an intersection of the profit curves exists. See the Appendix for a plot replicating Figure 2 based on numerical solutions to the model for the latter example.
} 
for any $r<\bar{r}\left(\alpha_{L}\right)$, i.e., $V_{b}^{*}\left(r, \alpha_{H}\right)<V_{b}^{*}\left(r, \alpha_{L}\right)$. Hence, $V_{b}^{*}\left(\bar{r}\left(\alpha_{L}\right), \alpha_{H}\right) \leq$ $V_{b}^{*}\left(\bar{r}\left(\alpha_{L}\right), \alpha_{L}\right)$ such that $\widehat{r}$ coincides with $\bar{r}\left(\alpha_{L}\right)$, and the shaded area does not exist. Hence, the principal favors the more envious agents over the less envious ones only if contracts with the latter type of agents are infeasible.

The following corollary summarizes the above derived insights with respect to the beneficial effects of envy regarding the profitability of relational contracts.

Corollary 1. Suppose that performance is non-verifiable and condition (14) is satisfied, and let $\alpha_{H}>\alpha_{L} \geq 0$.

Then there exists a range of interest rates $\widehat{r}<r \leq \bar{r}\left(\alpha_{H}\right)$ for which the principal prefers to employ more envious agents over less envious ones. In particular,

(i) if the difference in the agents' degree of envy, $\alpha_{H}-\alpha_{L}$, is sufficiently small, then $\widehat{r}<\bar{r}\left(\alpha_{L}\right)$. Thus, there is a range of interest rates $\widehat{r}<r \leq \bar{r}\left(\alpha_{L}\right)$ for which relational contracts are feasible with both more and less envious agents but profits with more envious ones are larger (see Figure 2).

(ii) if the difference in the degrees of envy, $\alpha_{H}-\alpha_{L}$, is sufficiently large, then $\widehat{r}=\bar{r}\left(\alpha_{L}\right)$, and profits with more envious agents exceed profits with less envious ones only if relational contracts with the latter are infeasible.

To put it differently, the principal definitely prefers to employ more envious over less envious agents whenever commitment is feasible only with more envious ones. Given that agents are not too different with respect to their propensities for envy, the same holds true for an extended range of interest rates for which, albeit contracts with both types of agents feasible, profits with more envious agents exceed those with less envious ones.

\section{Discussion and Extensions}

In the preceding sections we have analyzed peer-independent performance pay and focused on the trade-off between credibility and the costs of inequity aversion. In doing so we have ignored contracts based upon peer-dependent performance evaluation like rank-order tournaments and group bonus contracts. However, these alternative compensation schemes have interesting features in our setup. In particular, the former avoids credibility problems 
altogether. Yet, as we will show, this comes at the cost of a larger inequity premium. At the other extreme, a group bonus contract excludes the possibility of unequal pay. We find, however, that it amplifies the credibility problem. In the following, we briefly outline the two alternative types of compensation contracts for the case of envious agents and discuss the implications for our results. In particular, in sections 4.1 and 4.2 , we verify that the restriction to individual bonus contracts is meaningful for a range of sufficiently high interest rates. Moreover, in section 4.3, we demonstrate that employing more envious agents may still be preferred by the principal, even if she has the choice between contracts based on individual, group, or relative performance.

\subsection{Group Bonus Scheme}

In a group scheme, the principal offers each agent a compensation contract $\left\{w_{B}, B_{Y_{i} Y_{j}}\right\}$, where $w_{B}$ is a guaranteed fixed wage and $B_{Y_{i} Y_{j}}$ a (per-worker) group bonus which is paid contingent upon both agents' performances $Y_{i}$ and $Y_{j}$ in the respective period. Whenever paid out, the group bonus is paid to both agents such that inequity in payoffs never occurs. Depending on the signals' realizations, the group incentive scheme allows for the implementation of three different bonus payments, $B_{01}, B_{10}$, and $B_{11}$. A thorough analysis of the group scheme under non-verifiable performance is conducted by Kragl (2009). In the following, we summarize some of her results which are relevant for the current analysis and their intuition.

In the repeated game, the optimal group scheme implements the smallest possible bonus payment for a given level of effort in order to facilitate credibility. Depending on the value of $p(e)$ at the desired effort level, either of two group bonus schemes is optimal. ${ }^{23}$ With $p(e) \leq 0.5$, a group bonus is paid whenever at least one agent is successful. In contrast, with $p(e)>0.5$, a group bonus is paid only if both agents are simultaneously successful. All results concerning the comparison of the group to the individual bonus scheme equivalently hold for either case. In the following, we only outline the case $p(e) \leq 0.5$ and discuss the arising trade-off.

Assume that the principal promises to pay a bonus $B$ to both agents whenever at least one agent is successful. In the single-period game, agent

\footnotetext{
${ }^{23}$ For a comprehensive analysis and the derivation of this result see Kragl (2009).
} 
$i$ 's expected utility is

$$
E\left[U_{i} \mid e_{i}, e_{j}\right]=w_{B}+\left(p\left(e_{i}\right)+p\left(e_{j}\right)-p\left(e_{i}\right) p\left(e_{j}\right)\right) B-c\left(e_{i}\right), \quad i \neq j
$$

where $e_{i}$ and $e_{j}$ denote the respective effort levels of worker $i$ and his coworker $j$. Observe that the agents' inequity averse preference structure has no effect on their respective utilities in the presence of the group scheme. In the unique symmetric Nash equilibrium of the one shot game, the first-order condition of (15) yields the incentive-compatible bonus for implementing a given effort level $e$ :

$$
B(e)=\frac{c^{\prime}(e)}{(1-p(e)) p^{\prime}(e)}
$$

Comparing equations (6) and (16) reveals that the size of the incentivecompatible group bonus $B(e)$ exceeds the size of the individual bonus $b(e ; \alpha)$ for any given effort level $e$ and any level of $\alpha \geq 0$. Intuitively, the group bonus introduces a positive externality effect of an agent's effort on the other agent's expected payoff. As a result, the probability of obtaining the bonus is less responsive to changes in effort in the group scheme than in the individual scheme, and, hence, the group bonus must be larger to elicit an equivalent effort level. Moreover, in contrast to the individual scheme, in the group scheme there is no incentive-strengthening effect of envy.

In the repeated game, the principal sets $B, w_{B}$, and $e$ to maximize expected profits per agent and period subject to incentive compatibility, participation, and credibility constraints. Given that the participation constraint is binding, we can eliminate $w_{B}$ such that the principal's problem becomes:

$$
\begin{array}{ll}
V_{B}^{*}(r):=\max _{e, B} & V_{B}(e)=p(e)-c(e)-U_{0} \\
\text { s.t. } & (1-p(e)) p^{\prime}(e) B=c^{\prime}(e) \\
\left(\mathrm{IC}_{B}\right) & B \leq \frac{V_{B}(e)}{r}
\end{array}
$$

From the optimization program can be inferred that, in the group scheme, as long as the interest rate is such that the credibility constraint is not binding, first-best effort levels $e^{F B}$ can be implemented, regardless of the agents' propensity for envy. Observe that, by equation (10), this is also true for profits in the individual scheme for the case of non-envious agents, i.e., 
$V_{B}^{*}(r)=V_{b}^{*}(r ; 0)$. However, as the interest rate increases, in both types of contract the respective credibility constraints become binding at some interest rate. Since the group bonus is larger, $B\left(e^{F B}\right)>b\left(e^{F B} ; 0\right),\left(\mathrm{CC}_{B}\right)$ necessarily becomes binding for a lower value of $r$ than (CC). In other words, $V_{B}^{*}(r)$ starts declining for a smaller value of $r$ than $V_{b}^{*}(r ; 0)$.

Altogether, with non-envious agents, the principal is never worse off using an individual bonus contract as compared to using a group bonus contract, i.e., $V_{b}^{*}(r ; 0) \geq V_{B}^{*}(r)$. Moreover, in section 3 we have shown that for sufficiently large interest rates the principal prefers envious agents to non-envious agents using an individual bonus scheme for a range of interest rates. $^{24}$ Thus, a fortiori, for this range of interest rates, she also prefers the individual scheme to the group bonus scheme when agents are envious. We illustrate this result in Figure 3(a). Observe that the principal indeed prefers the individual bonus scheme for any interest rate $r>\widetilde{r}$ given that agents are envious.

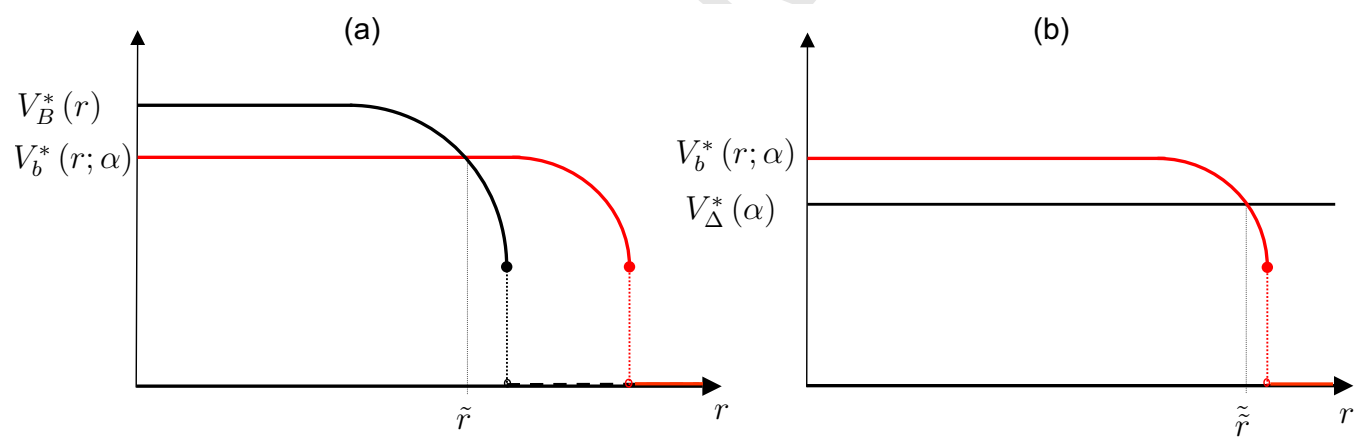

Figure 3: Profits in (a) the individual and the group scheme and (b) the individual scheme and the tournament for a given degree of envy, $\alpha>0$, provided that condition (14) is satisfied.

\subsection{Rank-order Tournament}

In a rank-order tournament, the principal does not face any credibility problem since she can ex ante commit to paying out a given sum of wages

${ }^{24}$ This holds when condition (14) is satisfied. See Proposition 3. 
in each period. ${ }^{25}$ In the current context, suppose she offers a fixed wage $w_{\Delta}$ to each agent and distributes a prize $\Delta$ among the agents in each period. In particular, she pays $\Delta$ to the winner if one exists. When contributions are equal, she pays $\frac{\Delta}{2}$ to each agent. ${ }^{26}$ In the single-period game, when exerting effort $e_{i}$ while his co-worker exerts effort $e_{j}$ agent $i$ 's expected utility is

$$
\begin{aligned}
E\left[U_{i} \mid e_{i}, e_{j}\right]= & w_{\Delta}+\left(1+p\left(e_{i}\right)-p\left(e_{j}\right)\right) \frac{\Delta}{2}-c\left(e_{i}\right) \\
& -\alpha p\left(e_{j}\right)\left(1-p\left(e_{i}\right)\right) \Delta, \quad i \neq j .
\end{aligned}
$$

In the symmetric Nash equilibrium of the one shot game, the first-order condition of (18) yields the incentive-compatible tournament prize for implementing effort $e$ :

$$
\Delta(e ; \alpha)=\frac{c^{\prime}(e)}{\left(\frac{1}{2}+\alpha p(e)\right) p^{\prime}(e)}
$$

Comparing equations (19) and (6), we find that the principal has to offer a tournament prize larger than the individual bonus for any $e$ and any $\alpha \geq 0$, $\Delta(e ; \alpha)>b(e ; \alpha)$. Intuitively, by paying out $\frac{\Delta}{2}$ when agents are both either successful or not, the principal avoids the credibility problem but weakens the incentives. Thus, to induce the same effort level, the principal is forced to raise $\Delta$ above $b$. Given that agents are envious, this is not innocuous. Specifically, it lowers the principal's profit as shown below.

The principal sets $\Delta, w_{\Delta}$, and $e$ to maximize expected profits per agent and period subject to incentive compatibility, participation, and credibility constraints. Given that the participation constraint is binding, we can eliminate $w_{\Delta}$, and the principal's problem becomes

$$
\begin{aligned}
V_{\Delta}^{*}(\alpha):= & \max _{e, \Delta} V_{\Delta}(e ; \alpha)=p(e)-c(e)-\alpha p(e)(1-p(e)) \Delta-U_{0}, \\
& \text { s.t. (19). }
\end{aligned}
$$

${ }^{25}$ Thus, a tournament is no relational contract as it solves the non-verifiability problem. In contrast to bonus contracts, however, tournaments suffer from collusion and sabotage, see e.g. Lazear (1989).

${ }^{26}$ Observe that in the current context, randomizing and paying $\Delta$ to only one of the agents would necessarily worsen the outcome due to the inequity aversion of the parties. In this sense, the tournament considered is relatively fair compared to standard tournament models with continuous signals, see e.g. Lazear and Rosen (1981). In particular, in our set-up the probability of equal signal realizations is non-zero as signals are binary. 
Observe that, by equations (10) and (20), tournament profits $V_{\Delta}^{*}(\alpha)$ are lower than profits in the individual incentive scheme $V_{b}^{*}(r ; \alpha)$ for any $\alpha>0$ and sufficiently small interest rates. ${ }^{27}$ This is due to the fact that, with envious agents, the relative payment structure induces even higher inequity costs than the individual bonus contract. ${ }^{28}$ Note, however, that in contrast to profits from the individual scheme, tournament profits are unaffected by an increase in the interest rate. Thus, for sufficiently high interest rates, the tournament outperforms the individual incentive scheme as the credibility problem becomes paramount in the latter. Figure 3(b) illustrates this result. For any interest rate $r<\widetilde{\widetilde{r}}$, the principal prefers the individual bonus contract to the tournamtent when agents are envious. This is true irrespective of whether condition (14) is fulfilled. Yet, if condition (14) holds, the individual bonus contract is superior to the tournament for a greater range of interest rates.

\subsection{Effects of an Increasing Propensity for Envy}

In the foregoing section we found that, with envious agents, the individual bonus structure remains preferable for a meaningful range of interest rates. In the remainder, we show that the intuition of Proposition 3 and Corollary 1 carries over to the comparative analysis of all three incentive schemes. In particular, we demonstrate that employing more envious agents may still be preferred by the principal even if she can select one of the three considered incentive contracts. Derived from the underlying functions' characteristics, Figure 4 qualitatively illustrates exactly such a case. ${ }^{29}$ It sketches optimal profits under the different incentive schemes for two different degrees of envy, $0<\alpha_{L}<\alpha_{H}$. The solid curves depict profits for $\alpha_{L}$, the dashed curves those for $\alpha_{H}$, respectively.

Note that profits in the group scheme are not affected by an increase in $\alpha$. In contrast, tournament profits decrease when $\alpha$ increases from $\alpha_{L}$ to $\alpha_{H}$ for any interest rate. By Proposition 2 and Corollary 1, for the considered

\footnotetext{
${ }^{27}$ Note that, for non-envious agents, the tournament is as least as good as the individual bonus scheme for any interest rate. However, once agents exhibit some propensity for envy, the individual contract is superior for a considerable range of interest rates.

${ }^{28}$ See Grund and Sliwka (2005) for a comprehensive analysis of the inequity costs in tournaments.

${ }^{29}$ We replicate Figure 4 by plotting a numerical example in the Appendix.
} 


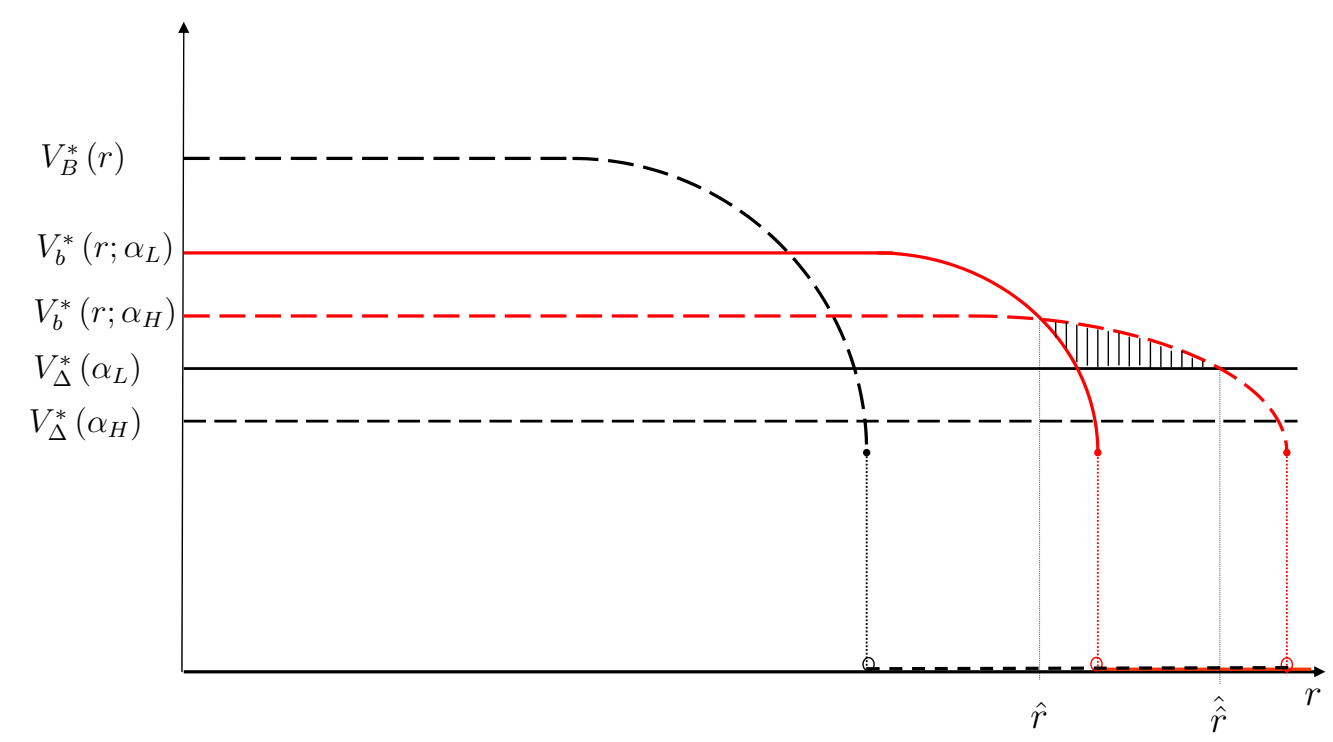

Figure 4: Profits in the individual scheme, the group scheme, and the tournament for two degrees of envy, $\alpha_{H}>\alpha_{L}>0$, given that condition (14) is satisfied.

increase in $\alpha$, profits in the individual incentive scheme decrease in $\alpha$ for interest rates $r<\widehat{r}$ but increase in $\alpha$ for interest rates $r>\widehat{r}$ as long as a contract is feasible and given that condition (14) holds. The figure reveals that for any interest rate $r \in(\widehat{r}, \widehat{r})$, the principal indeed prefers to use the individual bonus scheme and to employ more envious agents rather than to implement a tournament with less envious agents and certainly rather than to implement a group scheme. The shaded area depicts the supplemental profit the principal may realize by employing more envious agents under an individual bonus contract. Observe that for any pair $\left(\alpha_{L}, \alpha_{H}\right)$ such a region exists only if $V_{b}^{*}\left(0 ; \alpha_{H}\right)>V_{\Delta}^{*}\left(\alpha_{L}\right)$. This condition implies that the difference $\alpha_{H}-\alpha_{L}$ must not be too large. Moreover, a sufficient condition for the region to exist is $V_{b}^{*}\left(\widehat{r} ; \alpha_{H}\right)=V_{b}^{*}\left(\widehat{r} ; \alpha_{L}\right)>V_{\Delta}^{*}\left(\alpha_{L}\right)$. Geometrically, the two individual profit curves must hence intersect above the line depicting the tournament profit with less envious agents. ${ }^{30}$

\footnotetext{
${ }^{30}$ Given the functions used in Figure 1, e.g., for the pair $\left(\alpha_{L}=2.5, \alpha_{H}=3\right)$ these conditions are fulfilled. See the Appendix for the plot of the numerical solutions to the model for this example.
} 


\section{Concluding Remarks}

We consider optimal individual incentive schemes in a principal-agent relationship with two identical agents who exhibit horizontal disadvantageous inequity aversion. As there are only subjective performance measures available to evaluate the agents' performances, the bonus contracts are enforced in a reputational equilibrium.

The analysis focuses on the impact of the agents' propensity for envy on the principal's commitment power that determines the feasibility of the relational contract. There are two countervailing effects at work: On the one hand, as agency costs increase due to the presence of envy, the principal's profits from the contract decrease as agents become more envious. Thus, continuation of the relational contract becomes less attractive. On the other hand, envy serves as an incentive-strengthening device. This implies that the principal has to pay a lower bonus to implement the same effort given that agents are envious, thereby reducing her benefit from a one-time deviation. We identify a necessary and sufficient condition assuring that the principal's ability to commit increases as agents become more envious. This implies that the principal prefers to employ more envious agents over less envious ones for a range of high interest rates.

In our paper, we abstract from empathy captured via the parameter $\beta>0$ in the model by Fehr and Schmidt (1999). Some studies claim that people might actually be better off if their payoff exceeds the payoffs of others in their peer group, implying that these people are spiteful and/or show preferences for status. ${ }^{31}$ This is contrary to empathy and could be captured by $\beta<0$. Assuming these kinds of preferences, in addition to envy, would strengthen our results as status seeking and spitefulness respectively lead to stronger incentives on the one hand and act contrary to the expected disutility from envy on the other hand. ${ }^{32}$ Thus, the higher status concerns or spiteful behavior, the more probable the positive effect of envy on relational contracts is achieved.

To complete the analysis, we outline two alternative types of contracts, both based upon peer-dependent performance pay. First, we briefly consider

\footnotetext{
${ }^{31}$ See e.g. Loewenstein et al. (1989), Moldovanu et al. (2007), and Brown et al. (2008).

${ }^{32}$ See Grund and Sliwka (2005) for spitefulness in the context of tournaments.
} 
a group bonus contract which inherently avoids unequal outcomes and thus implies an inequity premium of zero, but amplifies the credibility problem. Second, we look at a rank-order tournament where the principal does not face a credibility problem, but increased inequity costs instead. We show that there exists a beneficial effect of envy, which carries over to the comparative analysis of all three incentive schemes.

\section{A. Appendix}

\section{A.1. Proofs for Section 2}

Proof of symmetry and uniqueness of the Nash-equilibrium in the singleperiod game. Both agents maximize their expected utility (4). The respective first-order conditions are given by

$$
\begin{aligned}
p^{\prime}\left(e_{i}\right) b-c^{\prime}\left(e_{i}\right)+\alpha p^{\prime}\left(e_{i}\right) p\left(e_{j}\right) b & =0, \\
p^{\prime}\left(e_{j}\right) b-c^{\prime}\left(e_{j}\right)+\alpha p^{\prime}\left(e_{j}\right) p\left(e_{i}\right) b & =0 .
\end{aligned}
$$

Combining both equations implies

$$
\begin{gathered}
\frac{c^{\prime}\left(e_{i}\right)}{p^{\prime}\left(e_{i}\right)\left(1+\alpha p\left(e_{j}\right)\right)}=\frac{c^{\prime}\left(e_{j}\right)}{p^{\prime}\left(e_{j}\right)\left(1+\alpha p\left(e_{i}\right)\right)} \\
\Leftrightarrow \frac{c^{\prime}\left(e_{i}\right)\left(1+\alpha p\left(e_{i}\right)\right)}{p^{\prime}\left(e_{i}\right)}=\frac{c^{\prime}\left(e_{j}\right)\left(1+\alpha p\left(e_{j}\right)\right)}{p^{\prime}\left(e_{j}\right)} .
\end{gathered}
$$

Both sides of equation (24) represent a function of the agent's effort level:

$$
\frac{c^{\prime}(e)(1+\alpha p(e))}{p^{\prime}(e)}
$$

Since (25) is monotonically increasing in e, equation (24) is satisfied if and only if $e_{i}=e_{j}=e$. To see this, consider the derivative of (25) with respect to effort:

$$
\frac{(1+\alpha p(e)) p^{\prime}(e) c^{\prime \prime}(e)+\alpha p^{\prime}(e)^{2} c^{\prime}(e)-p^{\prime \prime}(e) c^{\prime}(e)(1+\alpha p(e))}{p^{\prime}(e)^{2}}
$$

As $\alpha, p(e), p^{\prime}(e), c^{\prime \prime}(e), c^{\prime}(e)>0$, and $p^{\prime \prime}<0,(26)$ is strictly positive. Moreover, as $e$ maximizes the agents' concave utility function (4), the equilibrium is also unique. 


\section{A.2. Proofs for Section 3}

Proof of Proposition 3. Differentiation of $\bar{r}$ yields

$$
\frac{\partial \bar{r}}{\partial \alpha}=\frac{\left(\left.\frac{\partial V_{b}}{\partial e}\right|_{e=\bar{e}} b-\left.V_{b} \frac{\partial b}{\partial e}\right|_{e=\bar{e}}\right) \frac{\partial e}{\partial \alpha}+\left.\frac{\partial V_{b}}{\partial \alpha}\right|_{e=\bar{e}} b-\left.V_{b} \frac{\partial b}{\partial \alpha}\right|_{e=\bar{e}} .}{b^{2}}
$$

The system (13) implies

$$
\left.\frac{\partial V_{b}}{\partial e}\right|_{e=\bar{e}} b(\bar{e} ; \alpha)-\left.V_{b}(\bar{e} ; \alpha) \frac{\partial b}{\partial e}\right|_{e=\bar{e}}=0 .
$$

With equation (28), (27) simplifies to

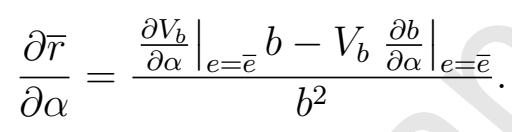

To decide upon the effect of $\alpha$ on $\bar{r}$ the sign of equation (29) is crucial:

$$
\operatorname{sign}\left(\frac{\partial \bar{r}}{\partial \alpha}\right)=\operatorname{sign}\left(\left.\frac{\partial V_{b}}{\partial \alpha}\right|_{e=\bar{e}} b-\left.V_{b} \frac{\partial b}{\partial \alpha}\right|_{e=\bar{e}}\right)
$$

Substituting $V_{b}$ as given in equation (10) and with

$$
\frac{\partial V_{b}(\bar{e} ; \alpha)}{\partial \alpha}=-b(1-p(\bar{e})) p(\bar{e})-\left.\alpha(1-p(\bar{e})) p(\bar{e}) \frac{\partial b}{\partial \alpha}\right|_{e=\bar{e}}
$$

equation (30) further simplifies to

$$
\operatorname{sign}\left(\frac{\partial \bar{r}}{\partial \alpha}\right)=\operatorname{sign}\left(-b^{2}(1-p(\bar{e})) p(\bar{e})-\left(p(\bar{e})-c(\bar{e})-U_{0}\right) \frac{\partial b}{\partial \alpha}\right) \text {. }
$$

With $b(\bar{e} ; \alpha)=\frac{c^{\prime}(\bar{e})}{(1+\alpha p(\bar{e})) p^{\prime}(\bar{e})}$ as given in $(6)$ and

$$
\frac{\partial b(\bar{e} ; \alpha)}{\partial \alpha}=-\frac{c^{\prime}(\bar{e}) p(\bar{e}) p^{\prime}(\bar{e})}{\left((1+\alpha p(\bar{e})) p^{\prime}(\bar{e})\right)^{2}}
$$

equation (31) results in

$$
\operatorname{sign}\left(\frac{\partial \bar{r}}{\partial \alpha}\right)=\operatorname{sign}\left(-c^{\prime}(\bar{e})(1-p(\bar{e}))+\left(p(\bar{e})-c(\bar{e})-U_{0}\right) p^{\prime}(\bar{e})\right) .
$$

Thus,

$$
\frac{\partial \bar{r}}{\partial \alpha}>0 \quad \text { iff } \quad p(\bar{e})>\frac{\left(c(\bar{e})+U_{0}\right) p^{\prime}(\bar{e})+c^{\prime}(\bar{e})}{p^{\prime}(\bar{e})+c^{\prime}(\bar{e})}
$$




\section{A.3. Numerical Examples and Plots}

\section{A.3.1. The effect of envy on the interest thresholds}

For the following numerical example we assume $p(e)=1-\exp (-e)$ and $c(e ; K)=K e^{2}$ such that condition (14) is satisfied. We consider two exemplary degrees of envy $\left(\alpha_{L}=0, \alpha_{H}=1\right)$ and two values of $U_{0}$ and $K$, respectively. The table below lists numerical solutions to our model for the interest thresholds $\underline{r}(\alpha)$ and $\bar{r}(\alpha)$. The table illustrates the effect of envy on the principal's commitment power as it shows the increase in the respective interest threshold levels that results from an increase in $\alpha$.

\begin{tabular}{|l|l|l|l|l|l|}
\hline \hline \multicolumn{2}{|l|}{} & \multicolumn{2}{l|}{ lower interest threshold $\underline{r}(\alpha)$} & \multicolumn{2}{l|}{ upper interest threshold $\bar{r}(\alpha)$} \\
\hline \hline$U_{0}$ & $K$ & $\underline{r}(0)$ & $\underline{r}(1)$ & $\bar{r}(0)$ & $\bar{r}(1)$ \\
\hline & & & & & \\
\hline 0.36 & 0.075 & 0.25 & 0.39 & 0.53 & 0.59 \\
\hline 0.39 & 0.075 & 0.22 & 0.32 & 0.43 & 0.45 \\
\hline 0.39 & 0.05 & 0.28 & 0.51 & 0.74 & 0.93 \\
\hline \hline
\end{tabular}

The examples reveal a converse impact of both parameters, $U_{0}$ and $K$, on the magnitude of the effect of envy; with decreasing values of each, the spans $\bar{r}(1)-\bar{r}(0)$ and $\underline{r}(1)-\underline{r}(0)$ increase. Consider, for example, the upper interest threshold. When $U_{0}$ falls from 0.39 to 0.36 and $K$ remains constant, the difference in the interest levels increases from $2 \%$ to $6 \%$. With $U_{0}$ constant, a decrease in $K$ from 0.075 to 0.05 causes an increase in the difference of the upper thresholds from $2 \%$ to $19 \%$.

Additionally, the plots in Figure 5 below graphically illustrate the effect of the parameters $U_{0}$ and $K$ on our results for the functional forms given above and for a continuous range of different parameter values. The left picture presents their impact on the magnitude of the feasibility-enhancing effect of envy for a change of $\alpha$ from 0 to 1 as it plots the difference of the respective upper interest thresholds. The right picture shows the impact on the upper interest threshold level for $\alpha=0.2$. 
Distance of $\bar{r}(\alpha=0)$ and $\bar{r}(\alpha=1)$

Level of $\bar{r}(\alpha=0.2)$
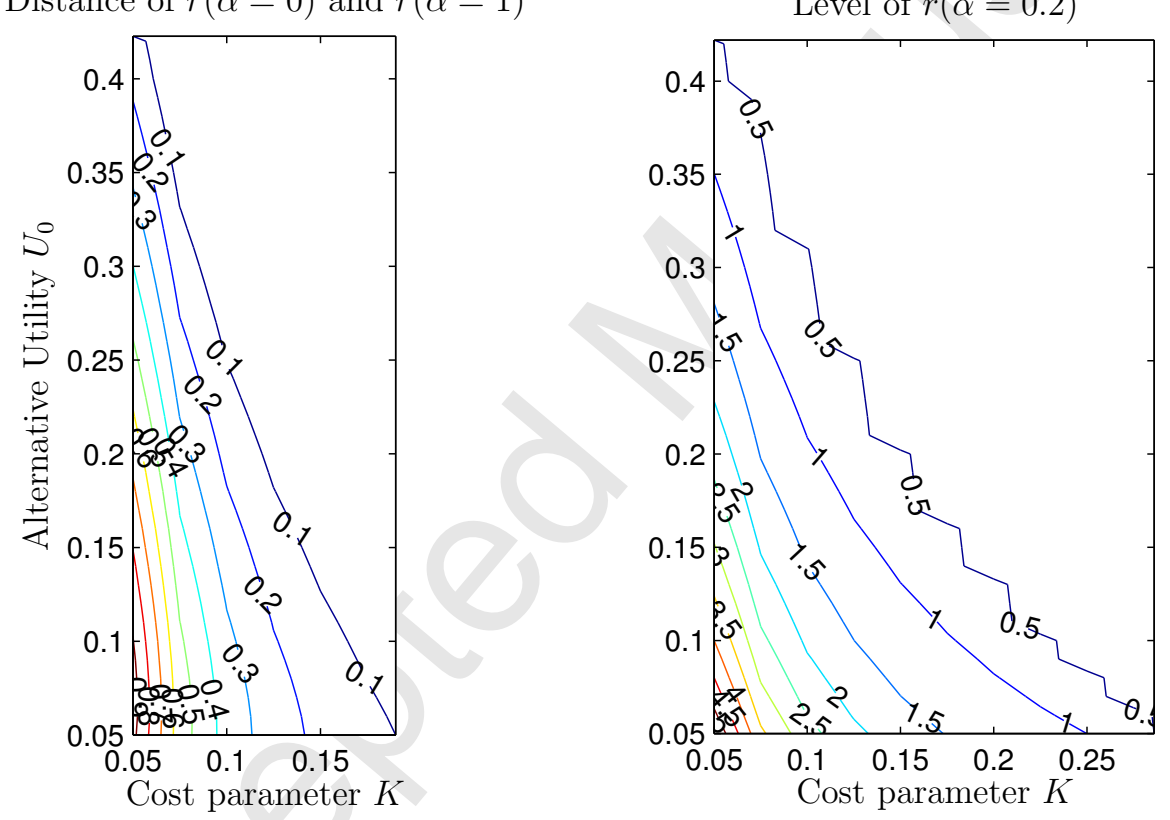

Figure 5: Effects of $U_{0}$ and $K$ on the magnitude of the feasibility-enhancing effect of envy (left) and the level of the upper interest threshold (right). 


\section{A.3.2. Comparison of individual bonus scheme, group bonus scheme, and} tournament

Numerically solving for the principal's profits in the repeated game, $V_{b}^{*}(r ; \alpha)$, $V_{B}^{*}(r), V_{\Delta}^{*}(\alpha)$, we replicate Figure 4 and thus implicitly Figure 2. As before, we assume $p(e)=1-\exp (-e), c(e)=\frac{1}{8} e^{2}$, and $U_{0}=0.1$. The following plot in Figure 6 exemplifies the impact of envy on the relative profitability of the incentive schemes with $\alpha_{L}=2.5$ and $\alpha_{H}=3.0$ based on the numerical solutions to the model for the example functions.

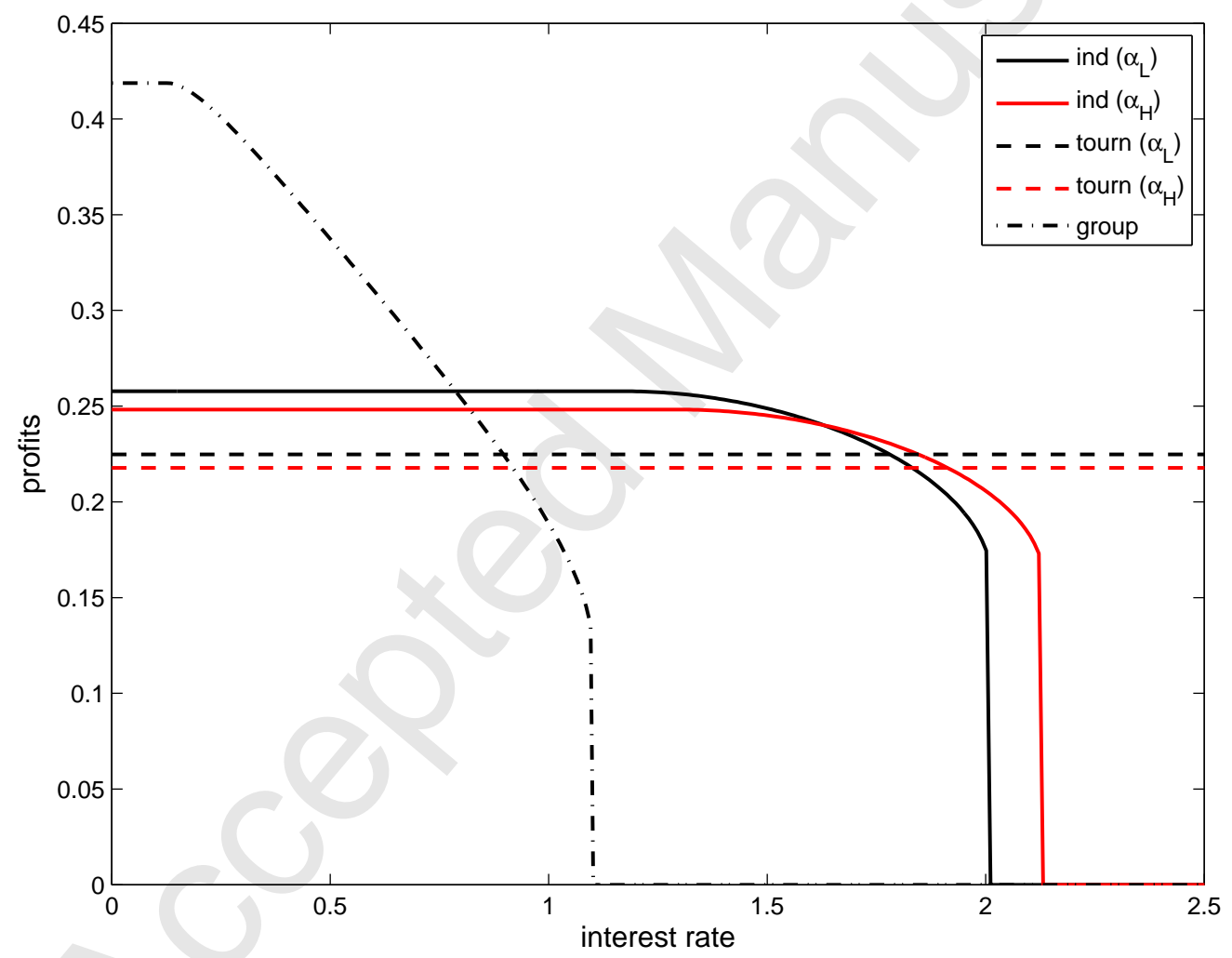

Figure 6: Plot of the profits in the individual scheme, the group scheme, and the tournament for two degrees of envy, $\alpha_{H}=3.0$ and $\alpha_{L}=2.5$.

\section{References}

Alesina, A., Di Tella, R., MacCulloch, R., 2004. Inequality and happiness: Are Europeans and Americans different? Journal of Public Economics 
88, 2009-2042.

Baker, G., Gibbons, R., Murphy, K.J., 1994. Subjective performance measures in optimal incentive contracts. The Quarterly Journal of Economics 109, 1125-56.

Baker, G., Gibbons, R., Murphy, K.J., 2002. Relational contracts and the theory of the firm. The Quarterly Journal of Economics 117, 39-84.

Bartling, B., von Siemens, F., 2007. The intensity of incentives in firms and markets: Moral hazard with envious agents. Discussion Paper 115, SFB/TR 15 Governance and the Efficiency of Economic Systems.

Berg, J., Dickhaut, J., McCabe, K., 1995. Trust, reciprocity, and social history. Games and Economic Behavior 10, 122-142.

Bewley, T.F., 1998. Why not cut pay? European Economic Review 42, 459490.

Bolton, G.E., Ockenfels, A., 2000. ERC: A theory of equity, reciprocity, and competition. American Economic Review 90, 166-193.

Brown, G.D.A., Gardner, J., Oswald, A., Qian, J., 2008. Does wage rank affect employees' well-being? Industrial Relations 47, 355-389.

Bull, C., 1987. The existence of self-enforcing implicit contracts. The Quarterly Journal of Economics 102, 147-59.

Corneo, G., 2001. Inequality and the state: Comparing U.S. and German preferences. Annales d' Economie et de Statistique 63-64, 283-296.

Demougin, D., Fluet, C., 2003. Inequity aversion in tournaments. Working Paper 03-22, CIRPÉE.

Demougin, D., Fluet, C., 2006. Group vs. individual performance pay when workers are envious. In Demougin, D., Schade, C. (Eds.), Contributions to Entrepreneurship and Economics - First Haniel-Kreis Meeting on Entrepreneurial Research. Duncker \& Humblot Verlag.

Falk, A., Fischbacher, U., 2006. A theory of reciprocity. Games and Economic Behavior 54, 293-315. 
Fehr, E., Gächter, S., Kirchsteiger, G., 1997. Reciprocity as a contract enforcement device: Experimental evidence. Econometrica 65, 833-860.

Fehr, E., Kirchsteiger, G., Riedl, A., 1998. Gift exchange and reciprocity in competitive experimental markets. European Economic Review 42, 1-34.

Fehr, E., Schmidt, K.M., 1999. A theory of fairness, competition and cooperation. Quarterly Journal of Economics 114, 817-868.

Goranson, R.E., Berkowitz, L., 1966. Reciprocity and responsibility reactions to prior help. Journal of Personality and Social Psychology 3, 227-232.

Grund, C., Sliwka, D., 2005. Envy and compassion in tournaments. Journal of Economics \& Management Strategy 14, 187-207.

Hart, O., 2001. Norms and the theory of the firm. University of Pennsylvania Law Review 149, 1701-1715.

Holmström, B., 1981. Contractual models of the labor market. American Economic Review 71, 308-13.

Isaksson, A.S., Lindskog, A., 2007. Preferences for redistribution - a crosscountry study in fairness. Working Papers in Economics 258, Göteborg University.

Kragl, J., 2009. Group vs. individual performance pay in relational employment contracts when workers are envious. European Business School Research Paper 09-09, European Business School (EBS) Wiesbaden.

Kräkel, M., 2008. Emotions in tournaments. Journal of Economic Behavior \& Organization 67, 204-214.

Kvaløy, O., Olsen, T.E., 2006. Team incentives in relational employment contracts. Journal of Labor Economics 24, 139-170.

Lazear, E.P., 1989. Pay equality and industrial politics. Journal of Political Economy 97, 561-80.

Lazear, E.P., Rosen, S., 1981. Rank-order tournaments as optimum labor contracts. Journal of Political Economy 89, 841-64. 
Levin, J., 2002. Multilateral contracting and the employment relationship. The Quarterly Journal of Economics 117, 1075-1103.

Levin, J., 2003. Relational incentive contracts. American Economic Review $93,835-857$.

Loewenstein, G.F., Thompson, L., Bazerman, M.H., 1989. Social utility and decision making in interpersonal contexts. Journal of Personality and Social Psychology 57, 426-41.

MacLeod, W.B., Malcomson, J.M., 1989. Implicit contracts, incentive compatibility, and involuntary unemployment. Econometrica 57, 447-80.

Moldovanu, B., Sela, A., Shi, X., 2007. Contests for status. Journal of Political Economy 115, 338-367.

Moriguchi, C., 2005. Implicit contracts, the great depression, and institutional change: A comparative analysis of U.S. and Japanese employment relations, 1920-1940. The Journal of Economic History 63, 625-665.

Okun, A.M., 1980. The invisible handshake and inflationary process. Challenge $22,5-12$.

Rabin, M., 1993. Incorporating fairness into game theory and economics. American Economic Review 83, 1281-1302.

Schöttner, A., 2008. Relational contracts, multitasking, and job design. Journal of Law, Economics, and Organization 24, 138-162. 